\title{
Ingested bony foreign body abutting thoracic aorta
}

\author{
Travis William Leahy, Jafri Kuthubutheen \\ ENT Department, Fremantle Hospital, Perth, Western Australia, Australia \\ Correspondence to Dr Travis William Leahy, travis.leahy@gmail.com
}

\section{Summary}

The authors present the case of a 38-year-old female who presented with an ingested oesophageal foreign body (lamb bone) following consumption of a casserole. The bone was initially not seen on plain $x$-ray but CT imaging revealed a $21 \times 20 \mathrm{~mm}$ pyramid shaped bone distending the proximal oesophageal mucosa and lodged only $2 \mathrm{~mm}$ from the aortic arch. Cardiothoracic surgery services were available on standby to perform an emergency thoracotomy in the event of any haemorrhage. However, the bone was removed successfully with rigid oesophagoscopy and the patient made a full recovery.

\section{BACKGROUND}

Irregularly-shaped ingested foreign bodies frequently lodge within the oesophagus, especially within the sites of anatomical constriction. However, most are usually not within such close proximity with indentation of major vascular structures by a sharp edge. Although there is a potential for vascular injury, this case indicates that it is possible to remove such foreign bodies using conventional rigid oesophagoscopy. The case also shows that it is possible to miss significant oesophageal foreign bodies on routine plain x-rays and that a CT scan should always be considered when the clinical suspicion is high.

\section{CASE PRESENTATION}

A 38-year-old female presented to a tertiary hospital emergency department after feeling a sharp, painful sensation in her throat following ingestion of a lamb casserole. The pain was worse on swallowing and radiated to the right chest and between her shoulder blades. The patient had managed to swallow water postingestion and

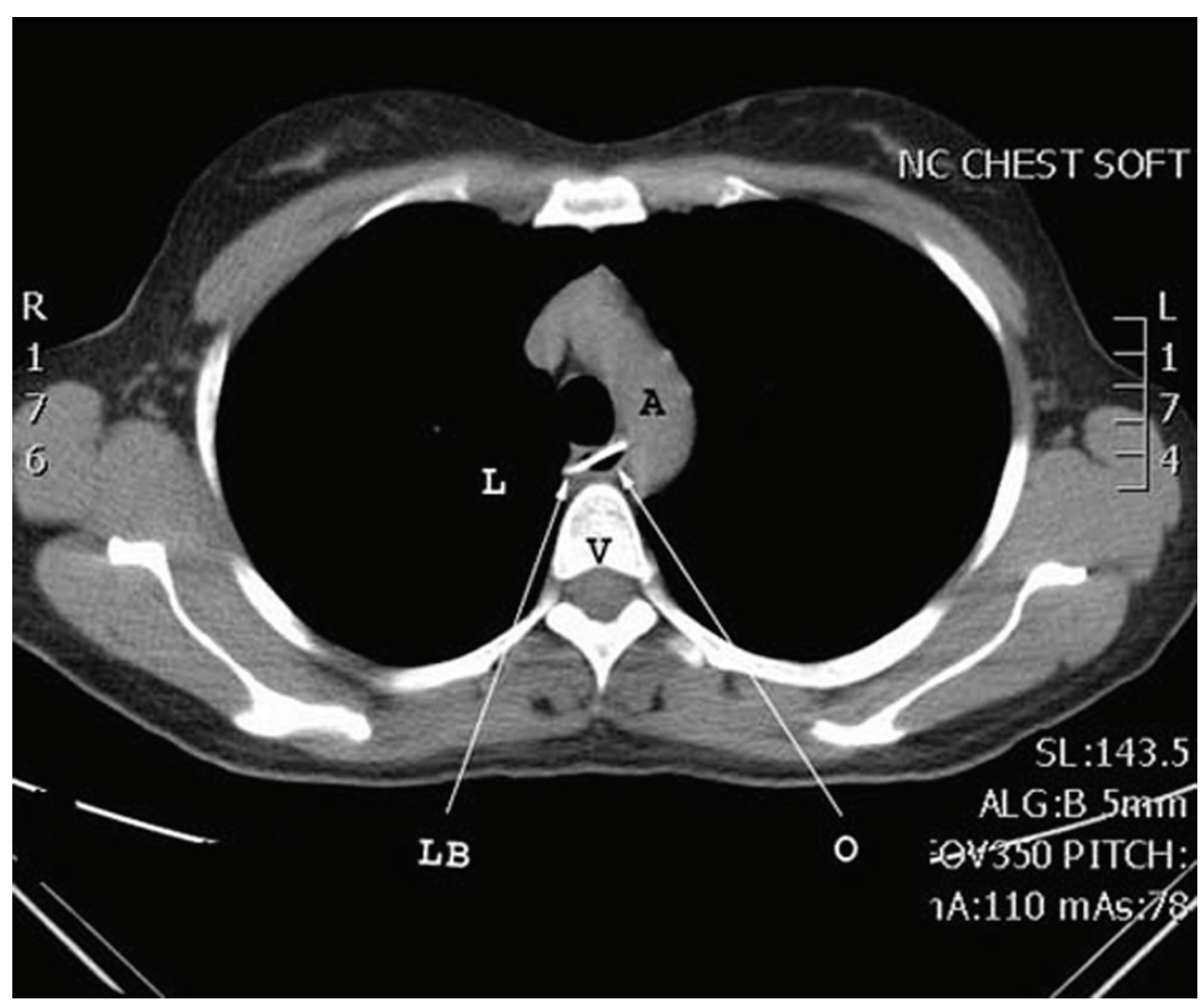

Figure 1 The lamb bone (LB) in the thoracic oesophagus $(0)$ at the level of the azygos vein and aortic arch $(A)$ appears radiologically confined to the oesophagus with no evidence of perforation or vascular injury. $L$, lung; $V$, vertebral body. 


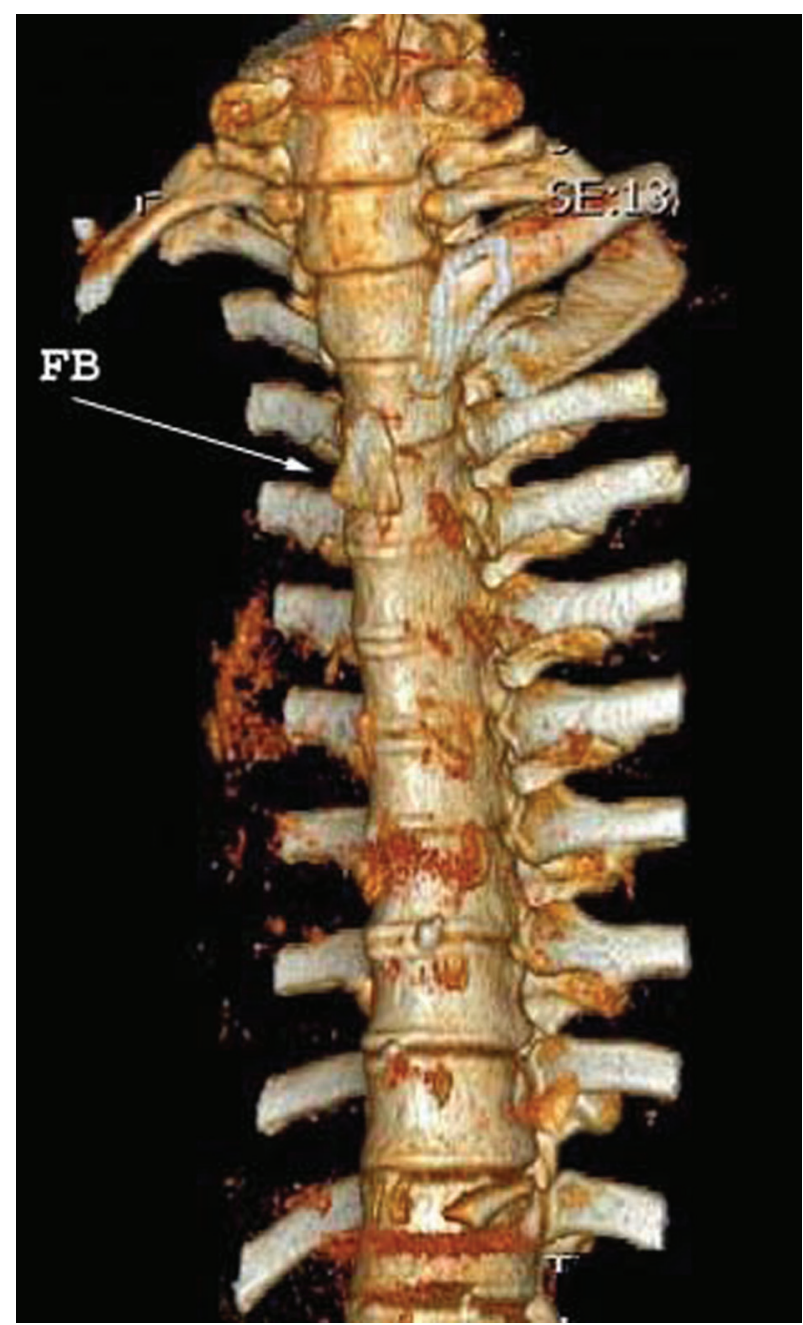

Figure 2 Bony CT reconstruction of the spine shows $20 \times 21$ $\mathrm{mm}$, triangular shaped foreign body (FB) anterior to T3-T4.

had not experienced any haemoptysis, haematemesis or dysphonia.

Examination was unremarkable and there were no added sounds elicited by auscultation in the neck or chest. The patient's voice remained unchanged. There was no abnormality on fiberoptic nasendoscopy.

\section{INVESTIGATIONS}

A diagnosis of an ingested foreign body was proposed and a chest and lateral neck $x$-ray were ordered. They showed no evidence of a foreign body.

It was then decided to proceed to CT imaging given the patients symptoms. The CT showed a bony foreign body within the thoracic oesophagus at the level of the azygos vein located $2 \mathrm{~mm}$ from the aortic arch (figures 1 and 2). It measured $20 \times 21 \mathrm{~mm}$ and was stretching the lumen of the oesophagus but there was no evidence of perforation or vascular injury.

The diagnosis was discussed with the patient, including the significance of the foreign body being lodged against a major vascular structure. Given the possibility of severe haemorrhage during retrieval of the foreign body, the cardiothoracic surgeons were asked to review the patient. The patient was then transferred to theatre for a rigid oesophagoscopy with cardiothoracic surgery on standby should there by the need for an urgent sternotomy, thoracotomy or cardiopulmonary bypass.

\section{DIFFERENTIAL DIAGNOSIS}

Initial

- Ingested foreign body lodged in the oesophagus

- Ingested foreign body that had passed to the stomach injuring oesophageal mucosa.

\section{After imaging}

- Ingested foreign body contained within the oesophageal wall (almost certain)

- Ingested foreign body with possible oesophageal tear

- Ingested foreign body with aorto-oesophageal fistula.

\section{TREATMENT}

A rigid oesophagoscopy was performed under general anaesthesia with support from on-site cardiothoracic surgeons and a cardiac anaesthetist.

A 40-cm rigid oesophagoscope was used and passed into the upper oesophagus atraumatically where the bone was visualised at $22 \mathrm{~cm}$ from the upper incisors. No recent or active bleeding was seen. Grasping forceps were used to engage the bone under direct vision and the bone was gently dislodged from the wall of the oesophagus and removed in its entirety without excessive traction required. A small mucosal tear on removal of the bone occurred with a small amount of blood.

Postoperatively, the patient was nursed on the ear, nose and throat ward. A postoperative chest x-ray was performed which did not reveal a pneumothorax or pneumomediastinum. The patient was kept nil-by-mouth for $48 \mathrm{~h}$ postprocedure during which the patient reported no chest pain or fever.

A contrast swallow study was performed using non-ionic contrast media at $48 \mathrm{~h}$ and showed no mucosal irregularities, perforations or structures. There was normal oesophageal motility. A nourishing fluid diet was commenced and a normal diet was introduced and tolerated within $24 \mathrm{~h}$.

\section{OUTCOME AND FOLLOW-UP}

The patient was discharged 3 days after the oesophagoscopy. Six-month follow-up with the patient showed no ill effects from her ingestion.

\section{DISCUSSION}

Foreign body ingestion is a common presentation to many Emergency Departments. Two studies looking at over 4500 combined cases of ingested foreign bodies demonstrated that fish bones are the most commonly ingested object followed by other animal bones including chicken and pork. ${ }^{1}$ ${ }^{2}$ Objects such as coins, dentures and toothpicks were also observed in these studies.

Common presenting features of ingested foreign bodies include pharyngeal discomfort, odynophagia, vomiting and retrosternal discomfort. ${ }^{1}$ In children, signs may also include refusal to take feeds and increased salivation. $^{2}$ Complications of oesophageal foreign bodies include oesophageal perforation, deep neck abscess, aortooesophageal fistular, mediastinitis and death. ${ }^{2-4}$ 
The patient in our case was extremely fortunate that she did not perforate her oesophagus given the proximity of the bone to the aorta. Oesophageal perforation has been reported in $0.14-0.87 \%$ of patients with ingested foreign body. ${ }^{2}{ }^{3}$ In cases involving perforation of the oesophagus and aorta, an aorto-oesophageal fistula often develops and is characterised by Chiari's triad of oesophageal injury, sentinal haemorrhage and then an asymptomatic interval followed by exsanguination. ${ }^{4}$

Treatment for ingested foreign body range from observation of the patient in the anticipation that the object will pass further into the digestive tract through to retrieval under direct vision by oesophagoscopy (flexible or rigid). ${ }^{12}$ In the case of oesophageal perforation, the objectives of management are to treat the infection, prevent continuing septic contamination, provide nutritional support and restore digestive tract continuity. ${ }^{5}$ Surgical treatments that may be utilised for perforation of the oesophagus include debridement of infected and necrotic tissues, suture of the perforation whenever possible, drainage, treatment of distal obstacles and parenteral or enteral hypercaloric alimentation. ${ }^{5} 6$

The role of definitive imaging is very important for accurate diagnosis and should not be underestimated, as was demonstrated in our case where plain radiography failed to identify any foreign body. A systematic review in 2007 looking at over 150 patients across four studies found that CT is more effective than plain radiography at identifying and excluding impacted oesophageal fish and chicken bones. ${ }^{7}$ However, they also noted that plain radiography is sensitive enough for positive results to warrant oesophagoscopy without further imaging, and should thus continue being utilised as the first line radiological investigation.

\section{Learning points}

- Ingestion of foreign bodies, particularly bones can be fatal and must therefore be investigated and managed without delay

- It is possible to miss significant oesophageal foreign bodies on routine plain $x$-rays

- Red flag symptoms of foreign body ingestion include odynophagia, vomiting, retrosternal discomfort and in children, increased salivation.

Competing interests None.

Patient consent Obtained.

\section{REFERENCES}

1. Lai AT, Chow TL, Lee DT, et al. Risk factors predicting the development of complications after foreign body ingestion. Br J Surg 2003;90:1531-5.

2. Nandi $\mathbf{P}, 0$ ng GB. Foreign body in the oesophagus: review of 2394 cases. $\mathrm{Br} \mathrm{J}$ Surg 1978;65:5-9.

3. Lam HCK, Woo JKS, van Hasselt CA. Esophageal perforation and neck abscess from ingested foreign bodies: treatment and outcomes. Ear Nose Throat J 2003;82:786

4. Macchi V, Porzionato A, Bardini R, et al. Rupture of ascending aorta secondary to esophageal perforation by fish bone. J Forensic SCi 2008;53:1181-4

5. Chirica M, Champault A, Dray X, et al. Esophageal perforations. J Visc Surg 2010:147:e117-28

6. Wu JT, Mattox KL, Wall MJ JrEsophageal perforations: new perspectives and treatment paradigms. J Trauma 2007:63:1173-84.

7. Das D, May G. Best evidence topic report. Is CT effective in cases of upper oesophageal fish bone ingestion? Emerg Med J 2007;24:48-9.

This pdf has been created automatically from the final edited text and images.

Copyright 2011 BMJ Publishing Group. All rights reserved. For permission to reuse any of this content visit

http://group.bmj.com/group/rights-licensing/permissions.

BMJ Case Report Fellows may re-use this article for personal use and teaching without any further permission.

Please cite this article as follows (you will need to access the article online to obtain the date of publication).

Leahy TW, Kuthubutheen J. Ingested bony foreign body abutting thoracic aorta. BMJ Case Reports 2011;10.1136/bcr.02.2011.3887, date of publication

Become a Fellow of BMJ Case Reports today and you can:

- Submit as many cases as you like

- Enjoy fast sympathetic peer review and rapid publication of accepted articles

- Access all the published articles

- Re-use any of the published material for personal use and teaching without further permission

For information on Institutional Fellowships contact consortiasales@bmjgroup.com

Visit casereports.bmj.com for more articles like this and to become a Fellow 